\title{
Extensive mucinous eccrine naevus following the lines of Blaschko: a new type of eccrine naevus
}

\author{
A. España; M. Marquina; M.A. Idoate*
}

Departments of Dermatology and *Pathology, University Clinic of Navarra, School of Medicine, University of Navarra, PO Box 4209, Pamplona, 31080 Navarra, Spain E-mail: aespana@unav.es

SIR, Epidermal naevi include several entities arising from the embryonic ectoderm. ${ }^{1}$ They may show a predominant component of nonorganoid (keratinocytes) and/or organoid naevi. ${ }^{2}$ Eccrine naevus (EN) is considered to be a type of epidermal naevus with eccrine differentiation. ${ }^{3}$ Several types of EN have been described. ${ }^{3}$ Recently, another type of EN, named mucinous EN (MEN), has been reported. ${ }^{4-6}$

A 32-year-old woman had several brownish and pruritic lesions over her left buttock and leg that had been present since she was 12 years old. She observed a progressive increase in size and number of the lesions, with increased sweating on and around them. Examination revealed several brownish, irregular nodules, 1-1.5 cm in diameter, and firm to palpation, along the lower left limb and following the lines of Blaschko (Fig. $1 \mathrm{a}-\mathrm{c})$. Iodine starch method showed increased sweating localized on the nodules. We made an excisional biopsy of one brownish nodule and of the contralateral nonaffected location. The number of ducts and secretory coils showed a mean of 28 elements in hamartomatous glands, and seven elements in the contralateral normal limb (each secretory coil or duct is considered an element) (Fig. 2a,b). The number of units of sweat glands was increased by around $40 \%$. Also, the hamartomatous glands showed an eccrine gland of diameter $2.4 \mathrm{~mm}$ against $0.2 \mathrm{~mm}$ in the normal glands, and an eccrine secretory coil diameter in cross-sections of the hamartomatous gland of $160 \mathrm{pm}$ vs. 75 $\mu \mathrm{m}$ in the normal eccrine glands. Abundant mucinous material around sweat glands stained strongly with Alcian blue, $\mathrm{pH}$ 2.5. The vessels in the connective tissue close to the hamartomatous gland were thicker than the same anatomical vessels in the normal glands. The arrector pili muscle appeared enlarged in the skin of the hamatomatous glands in contrast to the same structure in the reference skin (395- $\mu \mathrm{m}$ diameter in crosssections vs. $170 \mu \mathrm{m}$ in normal muscle).

Epidermal naevi are considered as hamartomatous disorders, following the lines of Blaschko. $^{7}$ Thus, each type of epidermal naevus represents the cutaneous manifestation of a different mosaic phenotype. ${ }^{8}$ These may occur at birth, infancy, or even later. $\mathrm{Ho}^{3}$ classified the epidermal naevus into six different variants: verrucous epidermal naevus, naevus sebaceus, naevus comedonicus, apocrine naevus, Becker's naevus and EN. Happle and Rogers ${ }^{2}$ classified the types of epidermal naevus according to their predominant component into keratinocyte (nonorganoid) naevi and organoid naevi such as sebaceous, follicular and sweat gland naevi (EN). 
Several types of EN have been described. Classically, it presents as a localized area of hyperhidrosis. It is a very rare lesion in which biopsy reveals an increase in the number and/or size of eccrine glands. ${ }^{9}$ It usually follows the distribution of the lines of Blaschko. It is sometimes associated with basaloid proliferation, and may show a mixture of organoid and nonorganoid components. Eccrine angiomatous hamartoma is characterized by an increased number of eccrine glands and numerous capillary channels. ${ }^{3}$ Lesions usually present in childhood and may be congenital. Hyperhidrosis is observed only sometimes. ${ }^{3}$ Porokeratotic EN clinically resembles a verrucous epidermal naevus, but pathological examination shows large numbers of focal parakeratotic plugs resembling cornoid lamellae. The eccrine ducts below the level of origin of the cornoid lamellae often show hyperplasia and a dilated lumen, but the eccrine glands show no abnormality. $^{2}$

EN has sometimes been associated with an increase of mucin production. ${ }^{3}$ Romer and Taira4 described a patient with a cutaneous erythematous nodule that had appeared 2 years before, localized on the lower right limb. It contained both eccrine and mucinous elements, and the authors coined the term MEN. Llombart et al. ${ }^{5}$ and Park et al. ${ }^{6}$ have described identical lesions in two other patients. These three cases of MEN and our patient present similar clinical and histological findings. Our case con-tributes additional information, in that the MEN lesions showed a distribution following the lines of Blaschko, with an extensive pattern along the lower left limb with multiple nodular lesions, and associated with focal hyperhidrosis.

The origin of MEN is not known. The lesions of MEN may be a result of the migration path of clones of genetically identical cells during fetal development, following the lines of Blaschko. However, during adulthood MEN might arise and become evident only after significant stimuli, e.g. growth factors stimulating fibroblasts, which may increase the synthesis of mucin. ${ }^{10}$

Our case highlights the hypothesis that this type of hamartomous lesion may be a subgroup of epidermal naevus with eccrine and mucinous differentation, with local or extensive location and with distribution following the lines of Blaschko. The description of more cases of MEN will give us more information in relation to the exact pathogenesis of this particular entity.

\section{REFERENCES}

1. Happle R. How many epidermal nevus syndromes exist? A clinicogenetic classification. J Am Acad Dermatol 1991; 25:550-6.

2. Happle R, Rogers M. Epidermal nevi. Adv Dermatol 2002; 18:175-201.

3. Ho VCY. Benign epithelial tumors. In: Fitzpatrick’s Dermatology in General Medicine (Freedberg IM, Eisen AZ, Wolff K, Austen KF, Goldsmith LA, Kafz SI, Fitzpatrick TB, eds) 5th edn. New York: McGraw-Hill, 1999; 884-5.

4. Romer JC, Taira JW. Mucinous eccrine nevus. Cutis 1994; 53:259-61.

5. Llombart B, Molina I, Monteagudo C et al. Mucinous eccrine nevus: an unusual lesion in a child. Pediatr Dermatol 2003; 20:137-9.

6. Park HS, Lee UH, Choi JC, Chun DK. Mucinous eccrine nevus. J Dermatol 2004; 31:687-9.

7. Bolognia JL, Orlow SJ, Glick SA. Lines of Blaschko. J Am Acad Dermatol 1994; 31:157-90. 
8. Happle R. Lethal genes surviving by mosaicism: a possible explanation for sporadic birth defects involving the skin. J Am Acad Dermatol 1987; 16:899906.

9. Ruiz-Erenchun F, Vazquez J, Mejuto FC et al. Localized unilateral hyperhidrosis: eccrine nevus. J Am Acad Dermatol 1992; 27:115-16.

10. Stücker M, Nowack U, Röchling A et al. Sweat gland proliferations in scleromyxedema. Am J Dermatopathol 1999; 21:259-64.

Conflicts of interest: none declared. 


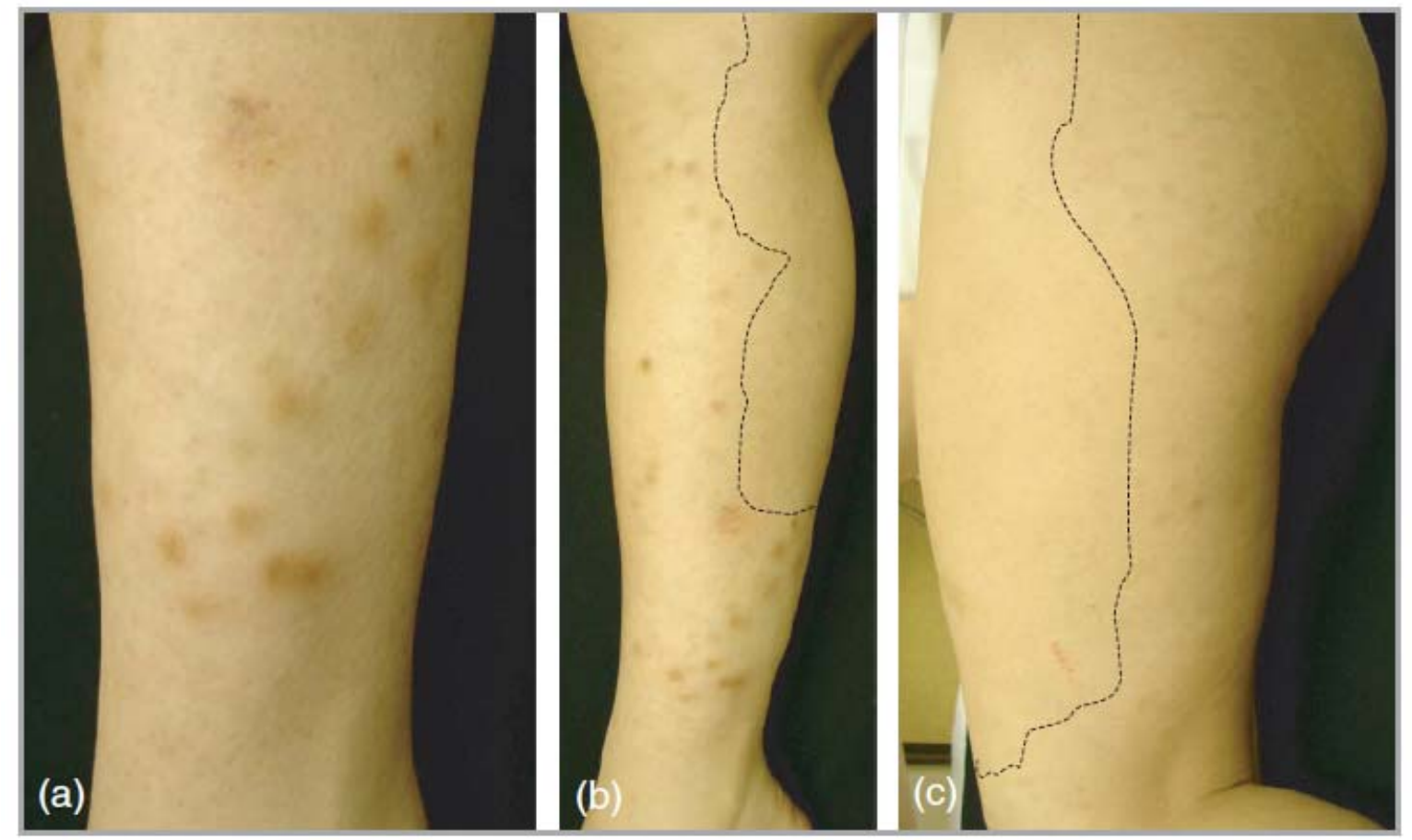

Figure 1. Several brownish, irregular nodules (a) along the lower left limb (b) and buttock (c) following the lines of Blaschko. 


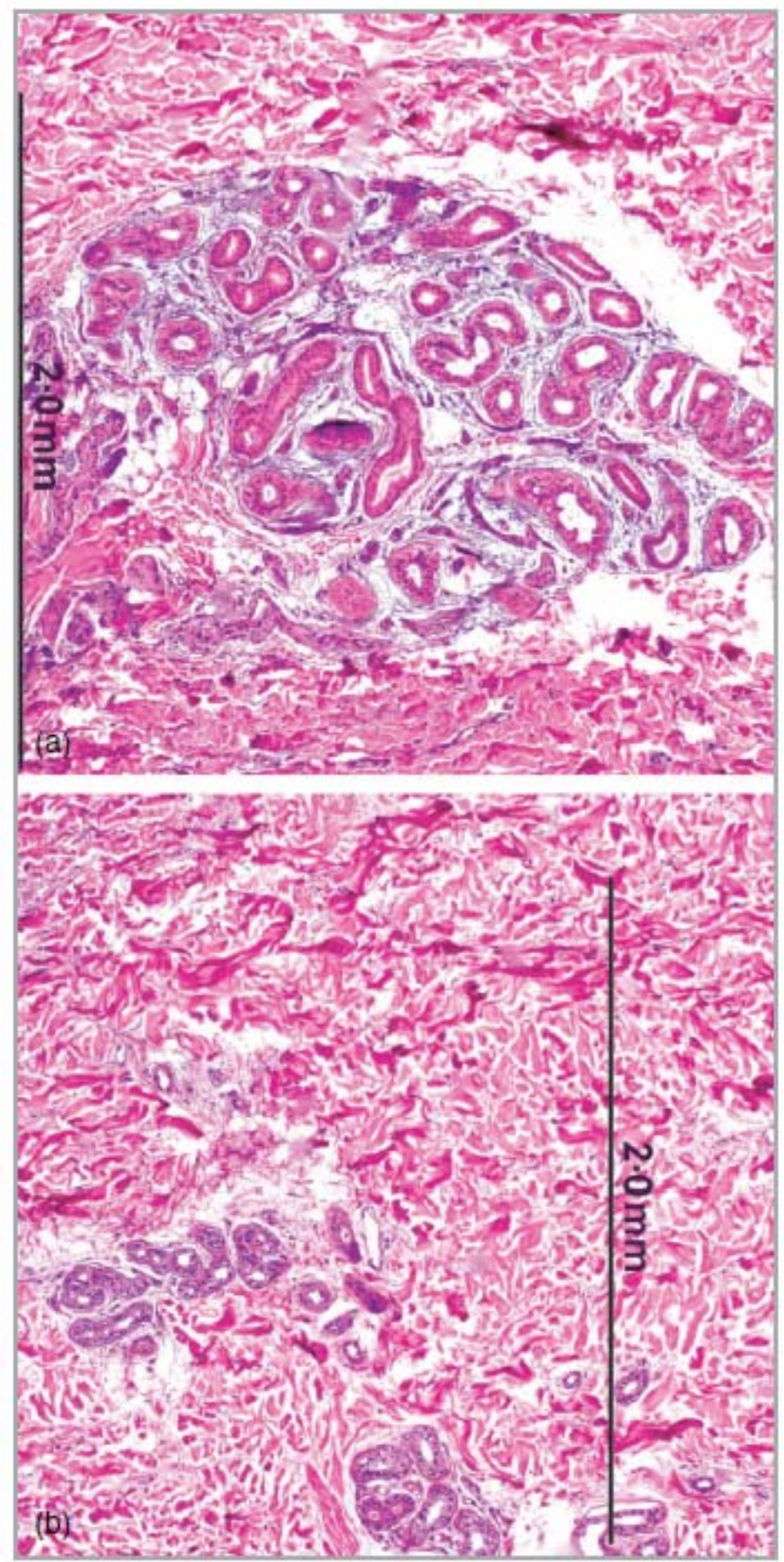

Figure 2. (a) Hyperplastic ducts and secretory coils can be seen in a hamartomatous eccrine gland. (b) There are more ducts and secretory coils in the hamartomatous gland than in the contralateral reference normal eccrine gland (haematoxylin and eosin; original magnification $\mathrm{x} 4$ ). 